\title{
SER PROFESSOR NA METRÓPOLE - DO SEU PAPEL POLÍTICO E SOCIAL
}

\author{
Carlos Bauer \\ UNINOVE \\ carlosbauer1960@yahoo.com.br
}

\section{RESUMO:}

O ensaio discute alguns papéis dos professores, procurando associá-los a um conjunto de temas amplos - políticas públicas, expansão e qualidade dos sistemas de ensino, trabalho, princípios, lutas, identidades, responsabilidades políticas e sua inserção nos movimentos sociais - que têm em comum o fato de constituírem os processos de urdidura de ações implicadas as lutas que se desenvolvem nas metrópoles.

Palavras-chave: Professor, Política Educacional, Identidade

\section{FOR TEACHERS IN CITY - DO YOUR PAPER AND SOCIAL POLICY}

\begin{abstract}
:
This essay discusses the role of teachers linked to outstanding themes: public polices, learning quality, education systems, identities, political responsabilities and social movements. All of this issues have in comum with been a teacher inside metropolis the battles for survival in it.
\end{abstract}

KeyWord: Professor, Educational Polices, Identity

\section{Introdução}

O ensaio discute alguns papéis dos professores, procurando associá-los a um conjunto de temas amplos - políticas públicas, expansão e qualidade dos sistemas de ensino, trabalho, princípios, lutas, identidades, responsabilidades políticas e sua inserção nos movimentos sociais - que têm em comum o fato de constituírem os processos de urdidura de ações implicadas as lutas que se desenvolvem nas metrópoles.

Cada um destes temas exige uma discussão particular. Na busca de sua articulação, optamos por apresentar algumas reflexões produzidas a partir do estudo alguns episódios da história recente, das últimas décadas, da situação social, das lutas e perspectivas de organização política dos trabalhadores no Brasil contemporâneo. Estamos cientes que estes temas são difíceis de combinar, mesmo enfrentando alguns problemas conceituais e os riscos de mencioná-los superficialmente.

Um deles diz respeito ao que chamamos de uma cultura política dominante nos movimentos sociais, nos movimentos de trabalhadores, dos explorados e oprimidos no Brasil desse período. Um outro ainda refere-se à composição, à estrutura social dos sujeitos, dos personagens que produzem esses movimentos e, finalmente, uma terceira temática que diz respeito à relação entre o mundo do trabalho e a educação. São essas três temáticas que buscaremos combinar neste ensaio. 


\section{A composição social dos movimentos sociais}

Como a ordem dos fatores não altera o resultado. Podemos começar pela segunda questão. Assim, optamos por trabalhar com o conceito de proletariado, de classe trabalhadora, como se encontra nos textos de inspiração marxista. Não nos sentiremos envergonhados, caso sejamos encarados como retrógrados por ficarmos presos à classe trabalhadora clássica, mas também não deixaremos de reconhecer à pertinência de determinados questionamentos relativos ao processo de formação da classe operária contemporânea.

Sim, porque consultando o Dicionário do pensamento marxista a definição de "proletariado", faz com que sejamos encaminhados para as páginas que procuram explicitar o que venha ser a classe operária. Redigido por Tom Bottomore, da Universidade de Sussex, o verbete nos remete ao papel político, revolucionário e a história desta classe social e segue, assim, procurando definir este papel através da pena de Marx, Engels e outros autores como Lênin, Lukács, Rosa de Luxemburgo, mencionando ainda, em tom polêmico, a Escola de Frankfurt, "cujo reconhecimento do caráter nãorevolucionário da classe operária ocidental levou à depreciação radical do seu papel e á busca de outras forças revolucionárias na sociedade moderna - particularmente durante as comoções de fins da década de 1960 - entre os estudantes, os jovens, os grupos étnicos explorados, as massas camponesas do Terceiro Mundo" (BOTTOMORE, 1988, p. 66).

Porém, ao falar da história desta classe, de sua consciência, do papel político e as transformações que por ventura tenha passado não define o que é, exatamente, o proletariado e a classe operária. Parece incorporar, nas entre linhas, uma idéia bastante presente no senso comum de que a classe trabalhadora é formada por aqueles que trabalham nas fábricas ou mesmo em outros setores da vida econômica, postulam direitos sindicais e ações grevistas.

Mas, como ficam aqueles que trabalham como professores nas escolas das grandes metrópoles brasileiras? Conceitos rígidos e cristalizados são capazes de dar conta e caracterizá-los adequadamente, inclusive, no interior das relações sociais ou culturais que a vida educacional produz?

A primeira resposta pressupõe um sim, pois podemos caracterizar o proletariado ou uma classe trabalhadora como aquela que se constitui por segmentos inteiros da população que não tem alternativa para sobreviver, exceto vendendo sua força de trabalho, não tem o controle sobre os chamados meios de produção, nem financeiros, nem jurídicos, não controla o setor de serviços, os culturais ou comerciais. Não obtêm lucros ou rendimentos de nenhuma espécie, resta-lhe então sua força de trabalho.

Aqui é interessante fazer um parêntesis. No mundo ocidental, como um todo e, particularmente, no Brasil ser caracterizado como trabalhador nem sempre é considerado algo confortante e inspirador de reconhecimento social. Historicamente, o trabalho está associado ao castigo, às torturas e sofrimentos físicos perpetrados pelos senhores, pelos patrões, pelas autoridades clericais, do Estado ou mesmo por Deus.

Etimologicamente controversa, a origem do conceito encontra-se no termo latino tripalium, literalmente o nome de um instrumento constituído de três estacas preparadas para aprisionar animais como bois ou mesmo cavalos difíceis de serem domesticados ou ferrados. Vulgarmente o termo passou a ser utilizado traduzindo as dificuldades encontradas diante das agruras da natureza ou a servidão do homem diante do próprio homem.

Do outro lado da história, não foram poucos aqueles que buscaram libertar os homens, as mulheres e as crianças das labutas e esforços cotidianos que não trazem 
nenhum tipo de satisfação ou aprimoramento espiritual. Como trabalho quase sempre se encontrava associado à monotonia, fatiga física e outros juízos depreciadores, trouxeram subsídios para que o mesmo fosse pensando como uma atividade gratificante e portadora de sentido existencial.

Com o advento da Revolução industrial, rapidamente, a inteireza da vida social passou a ser centralizada em torno de valores como produtividade, combate ao ócio e o trabalho erigido como redentor dos problemas e inquietações sociais. Uma nova ordem social estava em curso e nela todos - homens, mulheres e crianças - eram chamados a colaborar com sua laboriosa edificação.

Um exemplo do desenvolvimento de tais concepções e que se encontra relacionado com a questão da educação e do trabalho infantil é o que aparece relatado na obra de Paul Mantoux A Revolução Industrial no século XVIII, nesta, estudando a maneira em que as crianças eram pensadas ou negociadas em suas comunidades e destacando as condições em que o trabalho infantil se produzia nas manufaturas, o seu controle e a forma pelo qual o mesmo era remunerado, escreveu o autor:

Entrar para uma fábrica era, diziam, como ir para um quartel ou para uma prisão. [...] A maioria desses infelizes seres eram crianças assistidas, fornecidas - poderíamos dizer vendidas - pelas paróquias por elas responsáveis. Os manufatureiros, principalmente durante o primeiro período do maquinismo, quando as fábricas eram construídas fora das cidades, e, em geral, longe delas, teriam tido grande dificuldade para obter a mão-de-obra de que necessitavam em sua vizinhança imediata. Por seu lado, as paróquias só queriam se desembaraçar de suas crianças. Aconteciam verdadeiros negócios, vantajosos para ambas as partes, embora não para as crianças, que eram tratadas como mercadorias, entre os fabricantes e os administradores do imposto dos pobres. Cinqüienta, oitenta, cem crianças eram cedidas em bloco e enviadas, como gado, com destino à fábrica onde deveriam ficar fechadas durante longos anos. [...] Os operários se recusavam, e com razão, a mandar as suas. Sua residência, infelizmente, não durou muito tempo; levados pela necessidade, resignaram-se àquilo que, a princípio, tanto os havia horrorizado. [...] Longe de se indignarem, os contemporâneos achavam isso admirável. Yarranton recomendava a abertura de escolas de indústria, como vira na Alemanha, onde duzentas meninas fiavam sem descanso, sob a ameaça da palmatória de uma mestra, submetidos a um silêncio absoluto, e chicoteadas se não fiassem bem ou rápido o bastante. [...] De Föe, ao visitar Halifax, ficou maravilhado ao ver crianças de quatro anos ganharem a vida como adultos. [...] Abandonados ao arbítrio dos patrões, que os mantinha fechados em seus edifícios isolados, longe de qualquer testemunha que pudesse comover-se com seu sofrimento, padeciam uma escravidão desumana. O único limite para seu dia de trabalho era o esgotamento completo de suas forças: durava quatorze, dezesseis e até dezoito horas [...] Freqüentemente, para não paralisar o funcionamento das máquinas, o trabalho continuava sem interrupção, dia e noite. Nesse caso, eram formadas equipes que se revezavam: 'as camas não esfriavam nunca'. Os acidentes eram freqüentes, sobretudo no final dos dias de trabalho muito longos, quando as crianças, exaustas, ficavam trabalhando meio adormecidas; foram incontáveis os dedos arrancados, os membros esmagados pelas engrenagens (MANTOUX, s.d., p. 36). 
Para além de questões morais, na modernidade ocidental, às relações laborais estão associadas ao produtivismo, à maquinaria e a reprodução do capital. Ideologicamente, suas classes dirigentes deverão condenar o ócio e a indolência, mas também a força e a coerção serão utilizadas para impor as relações de trabalho no interior da sociedade burguesa.

Ironicamente, o trabalho será exaltado como uma fonte de riqueza, porém os que trabalham jamais terão acesso a ela. Como se diz popularmente: "quem trabalha não tem tempo de ganhar dinheiro", pelo contrário são prisioneiros de técnicas e métodos alienantes, de uma ferrenha disciplina controladora de sua força de trabalho, sua subjetividade e toda sua vida social.

A perspectiva de disciplinar a vida social encontrará na escola um importante aliado. Assumindo efetivamente sua responsabilidade com a reprodução social, contribuindo com a veneração do trabalho, formando pessoas dispostas a trabalhar sem questionar as condições materiais, o apresentando como única possibilidade de serem reconhecidos como cidadãos.

Nas periferias das grandes cidades brasileiras, os jovens e as crianças não têm alternativas: precisam procurar trabalho e se proletarizar o mais rápido possível, alcançando assim uma mínima dignidade e reconhecimento social.

Ressalta-se também que dispor de sua própria força de trabalho não significa dizer que a mesma possa ser naturalmente empregada na construção da sobrevivência de seu possuidor. Nem sempre isto será possível, não existe o pleno emprego na sociedade capitalista. $\mathrm{O}$ desemprego e as crises cíclicas trazem realidades que obrigam que a classe trabalhadora tenha que contar com outras possibilidades para sobreviver.

Resta saber se o homem que vende a sua alma ao diabo com o dinheiro que obtém pode alimentar os filhos?

O capitalismo impõe a amplos contingentes da humanidade o caráter de despossuídos, nega-lhes o direito fundamental e produz uma heterogeneidade entre os exploradores e explorados sem precedentes na história.

Mas as diferenças não são apenas sociais, políticas e econômicas, mas também ideológicas e culturais no mundo do trabalho. Dentro deste universo de complexa heterogeneidade, a classe trabalhadora procura encontrar pontos de uma unidade perdida. Algo intrínseco a esse processo é a divisão entre os trabalhadores formais e informais como operadores das formas como pensamos o trabalhador e as relações de trabalho na atualidade, ou seja: pelos seus aspectos jurídicos e legais e não pela posição que este ocupa na luta de classes ou mesmo na divisão social e internacional do trabalho.

Sob o capitalismo as condições de trabalho são precárias para quase todos os que vivem do próprio trabalho, aliás, como analisa István Meszáros:

[...] $\mathrm{Na}$ verdade, as conseqüências devastadoras da tendência contraditória de expulsar um grande número de trabalhadores do processo de trabalho, até mesmo nos países capitalistas mais avançandos, já são visíveis há muito tempo. Há vinte e cinco anos, argumentei que 'o problema já não é apenas o sofrimento dos trabalhadores sem qualificação, mas também o de um grande número de trabalhadores qualificados que, junto com o exército de desempregados, disputam o número desesperadamente pequeno de empregos disponíveis. A tendência da amputação "racionalizadora" já não se limita aos "ramos periféricos de uma indústria envelhecida", mas inclui alguns dos setores mais desenvolvidos e modernos da produção - da construção naval e aeronáutica à eletrônica, e da engenharia à tecnologia especial. Assim, já não estamos preocupados com os subprodutos "normais" e bem aceitos 
do "crescimento e desenvolvimento", mas com a sua paralisação; nem com problemas periféricos de "bolsões de subdesenvolvimento", mas com uma contradição fundamental do modo capitalista de produção em seu conjunto, que transforma até as maiores conquistas do "desenvolvimento", da "racionalização" e da "modernização" em pesos paralisantes de subdesenvolvimento crônico. E, mais importante de tudo, a ação humana que se encontra no lado dos que sofrem as conseqüências já não é constituída pela multidão socialmente imponente, apática e fragmentada de pessoas "desprivilegiadas", mas por todas as categorias de trabalhadores, qualificados ou sem qualificação: ou seja, objetivamente o total da força de trabalho da sociedade (MÉSZÁROS, 2002, p. 322-23).

Logo, precisamos pensar no que possibilita a reprodução do explorado. Neste caso, pensaríamos como os clássicos e nosso tema seria o que concerne ao proletariado produtivo, aquele que transforma a natureza com seu trabalho e que está inserido num ciclo econômico e produtivo e que imagina que a sua condição de classe é natural e não será jamais modificada, exceto pela obra revolucionária.

Mas, hoje as coisas estão modificadas, existem diferentes tipos de trabalhadores informais ou formais inseridos nos ciclos de acumulação, neles todos são explorados. E temos também trabalhadores não produtivos, que não transformam a natureza diretamente, como é o caso do professor.

Esse, aliás, raramente, tem certeza de que é um trabalhador, muito menos discute sobre como se dá a sua exploração no processo de reprodução do capital, tendo mesmo dificuldades de se localizar no interior do ciclo produtivo, do seu papel no processo de acumulação de capital.

O professor, muitas vezes, não consegue se entender como trabalhador, não são todos os que têm clareza de qual é a sua identidade e o papel ocupado na reprodução social, mas - tenha ou não consciência disso - se produz a sujeição do seu trabalho ao alienante fetichismo da mercadoria.

Por outro lado, ao contrário dos outros trabalhadores, quando inserido nas dinâmicas empregatícias dos serviços públicos, praticamente, não tem que se preocupar em se reproduzir como força de trabalho, ou seja, diferentemente de qualquer trabalhador, tem certeza de que conseguira trabalho, jamais estará desempregado e conseguirá seu trabalho docente, normalmente, anos a fio.

Afinal de contas, são alguns milhões de alunos matriculados nas escolas de educação básicas espalhadas por todo o país. Nas regiões metropolitanas de todo território nacional, o setor educacional vem crescendo substancialmente cada vez mais. Segundo dados do Instituto Nacional de Estudos e Pesquisas Educacionais Anísio Teixeira - Inep, o Censo Escolar da Educação Básica do ano de 2006 mostra que, do total de 203.931 escolas brasileiras, 92.172 estão localizadas em zona rural (45,19\%). A Região Norte é que tem maior proporção de escolas rurais em relação aos estabelecimentos urbanos: 71,65\%. A Região Nordeste possui $62,53 \%$ de suas escolas localizadas em zona rural, enquanto na Região Sul a proporção de escolas rurais em relação às urbanas é de $28,99 \%$. No CentroOeste este índice é de $22,83 \%$ e, no Sudeste, $19,41 \%$. Veja tabela abaixo: 


\section{Número de Estabelecimentos da Educação Básica, por Localização e Dependência Administrativa, segundo a Região Geográfica e a Unidade da Federação, em 29/3/2006}

\begin{tabular}{|c|c|c|c|c|c|c|c|c|c|c|c|}
\hline \multirow{3}{*}{ UF } & \multicolumn{11}{|c|}{ Estabelecimentos da Educação Básica } \\
\hline & \multirow{2}{*}{ Total } & \multicolumn{5}{|c|}{ Urbana } & \multicolumn{5}{|c|}{ Rural } \\
\hline & & Total & Federal & Estadual & Municipal & Privada & Total & Federal & Estadual & Municipal & Privada \\
\hline Brasil & 203.931 & 111.759 & 160 & 26.929 & 49.868 & 34.802 & 92.172 & 46 & 6.381 & 85.010 & 735 \\
\hline Norte & 25.322 & 7.178 & 15 & 2.452 & 3.453 & 1.258 & 18.144 & 5 & 1.665 & 16.403 & 71 \\
\hline Nordeste & 84.632 & 31.704 & 48 & 6.705 & 15.409 & 9.542 & 52.928 & 18 & 1.418 & 51.047 & 445 \\
\hline Sudeste & 57.744 & 46.532 & 62 & 10.615 & 19.049 & 16.806 & 11.212 & 10 & 1.455 & 9.596 & 151 \\
\hline Sul & 26.194 & 18.598 & 27 & 4.683 & 8.950 & 4.938 & 7.596 & 7 & 1.565 & 5.978 & 46 \\
\hline $\begin{array}{l}\text { Centro- } \\
\text { Oeste }\end{array}$ & 10.039 & 7.747 & 8 & 2.474 & 3.007 & 2.258 & 2.292 & 6 & 278 & 1.986 & 22 \\
\hline
\end{tabular}

\section{Área urbana concentra quase $90 \%$ das matrículas}

Das 55.942.047 matrículas da educação básica, coletadas pelo Censo 2006, 7.469.924 estão em áreas rurais do País. Isso significa que, ainda que em número de estabelecimentos haja quase metade de unidades de ensino fora dos centros urbanos, quando se fala em alunos constata-se que a maioria deles está concentrada nas cidades. Apenas13,35\% das matrículas da educação básica - que compreende o ensino infantil (creche e pré-escola), ensino fundamental, ensino médio, educação especial, educação de jovens e adultos e educação profissional de nível médio ou técnico - concentra-se nas áreas rurais do Brasil.

Fonte: Informativo $\mathrm{n}^{\circ} .149$ do Instituto Nacional de Estudos e Pesquisas Educacionais Anísio Teixeira - Inep - Endereco: http://www.inep.gov.br/informativo/2007/ed_149.htm

Quando olhamos o Brasil assim, pelo prisma de aproximadamente 56 milhões de alunos matriculados na escola básica, quando a gente olha para o progresso ou, melhor dizendo, para a expansão das experiências educacionais que vêm sendo implementadas na atualidade, podemos dizer que, em grande parte, são sobre essas diferenças, problemas e possibilidades acarretadas pela massificação educacional que temos de nos debruçar.

Mas achamos oportuno falar, antes disso, um pouco das lutas e perspectivas de organização e cultura política dos trabalhadores nas últimas décadas.

\section{A cultura política dos movimentos sociais}

O ponto de vista que nos interessa abordar, para contribuir com o entendimento dos professores como trabalhadores e os seus papéis como sujeitos e, por conseguinte, suas responsabilidades no interior dos processos de organização e lutas da classe trabalhadora no Brasil, referem-se à cultura política formadora ou dominante nos movimentos sociais que estes participaram na contemporaneidade.

Suas lutas e mobilizações ajudaram a escrever a história de todo aquele período que puseram abaixo a ditadura militar, desde os finais dos anos 1970 e início dos anos 1980, foi marcado por uma cultura política, na qual questão da luta dentro dos limites do capitalismo, dentro da legalidade e do campo institucional seria determinante e tinham um formidável potencial anticapitalista.

Esse potencial anticapitalista se refletia menos em declarações ideológicas, por exemplo, a afirmação da unidade dos explorados e do objetivo final do socialismo, mas 
principalmente, na força que tinham determinadas bandeiras e pautas de lutas que eram impossíveis de se acomodarem dentro da lógica do capital e dos seus formalismos jurídicos, políticos e sociais.

$\mathrm{E}$ eram reivindicações presentes, tanto nos movimentos dos trabalhadores em educação (CNTE, FASUBRA, ANDES), no popular, no sindical e até mesmo no MST. Algumas precisam ser lembradas aqui. Uma que sempre aparecia com muita força era o salário mínimo do DIEESE.

Todo documento de luta democraticamente votado nas assembléias o tinha presente, não se abria mão desse item na pauta, sabemos hoje, como sabíamos ontem, uma reivindicação impossível de ser absorvida pelo capital. Ela partia do que era essencial para as necessidades do trabalhador e não do que era possível a empresa ou o Estado remunerar pelo pagamento da força de trabalho que este adquire.

Sempre constando nas pautas reivindicativas o não pagamento da dívida externa, também seria impossível de ser aceito nas estruturas financeiras da época histórica da mundialização do capital. Outra ainda relacionada com os fluxos financeiros mundiais era o rompimento com o FMI, não se falava nem mesmo em renegociação com os organismos internacionais, era rompimento que se pedia.

Outra - julgada importantíssima nos processos de transformações sociais - era a Reforma Agrária. Não havia este silêncio perturbador, como hoje, sobre a importância destas medidas como parte de quaisquer programas políticos preocupados em questionar a monumental desigualdade social e a crescente concentração de renda no Brasil.

Naqueles dias era diferente, defendia-se a Reforma Agrária Radical ou mesmo a Reforma Agrária sob controle dos trabalhadores, deixando claro o compromisso com a extinção das grandes propriedades privadas. Não se falava em corrigir a estrutura agrária vigente preservando-se os latifúndios produtivos. Num congresso da CNTE ou do Andes, por exemplo, não era isso que se discutia. Nos seus grupos e no plenário destes encontros o que se discutia era a expropriação da grande propriedade.

Algo interessante de ser lembrado é que os que se debruçavam no estudo do marxismo e na discussão do socialismo encontravam nestes fóruns um solo fértil para semear suas inquietações societárias.

Essas reivindicações gerais e outras específicas, construídas e legitimadas por intermédio dos movimentos sociais chocavam-se violentamente com os planos de reorganização privatizantes em curso no mundo capitalista.

O que aconteceu na década de 1980, do ponto de vista do mundo trabalho, foi uma impressionante onda de mobilizações que muitos dos leitores conhecem bem e poderão ajudar no dimensionamento de sua importância histórica com seus escritos ou mesmo testemunhos verbais.

Em nossa caracterização, ao longo da década de 1980, foram as mobilizações dos trabalhadores que inviabilizaram a consertação neoliberal que já estava em curso em diferentes países e no Brasil tinha dificuldade de ser implantada e foi sendo retardada. As reivindicações e programas dos trabalhadores não poderiam jamais ser absorvidos por quaisquer projetos neoliberais ou afinados com as reformas que estavam em curso no seio da sociedade capitalista. Alguns momentos importantes deste processo foram à greve geral e campanha presidencial de 1989, precedidas das jornadas de lutas e vitórias eleitorais dos trabalhadores em 1988.

A greve geral foi um momento importante em nossa educação política. Não era uma greve qualquer como outras que já tinham sidos realizadas. Primeiro, porque estava longe de ser uma greve meramente economicista, de cunho corporativista e sindical. Os trabalhadores sindicalizados tiveram um papel decisivo em sua organização, porém os 
movimentos sociais, populares e diferentes segmentos da sociedade civil acabaram se envolvendo em sua urdidura e ações.

Em São Paulo, através de comandos de greves organizados por trabalhadores de várias categorias, os professores da rede pública subitamente viram-se envolvidos num movimento de toda classe e com práticas políticas e sociais muito distintas daquelas que estavam habituados a realizar.

De fato, no processo de preparação desta greve, não foram poucos os professores que se envolveram na organização dos seus comitês, visitaram fábricas, participaram de reuniões preparatórias nos bairros da periferia, assim também se relacionando com os movimentos populares e com suas práticas de enfrentamento com as forças policiais do Estado. Pode-se dizer que estávamos vivenciando uma aula magna de participação política dos trabalhadores.

O resultado das mobilizações e greves de 1988 e 89 foi o retardamento na aplicação das políticas reformistas governamentais. Mas tais demonstrações de força não foram suficientes e a questão do poder se mostrava presente na cotidianidade dos movimentos sociais em nosso país. Neste percurso, a campanha de Lula acabou aglutinando a ampla maioria dos que buscavam soluções para os mais sentidos problemas dos "de baixo" no Brasil. O caminho institucional foi priorizado e a campanha Brasil, urgente, Lula presidente, chegou ao segundo turno.

A partir daquele momento, tendo como prioridade o calendário eleitoral, iniciou-se um processo de cooptação dos movimentos populares e sindicais que chegaria até os nossos dias com este quadro de letargia, desmoralização ou acomodação da quase totalidade dos movimentos sociais diante do primeiro e do segundo governo Lula.

Foi à alternativa de luta institucional que foi priorizada e essa opção não surgiu da noite para o dia. Ao longo de toda década de 1980, os movimentos sociais e populares foram sendo cooptados e, no seu lugar, as ONGs se espalharam e se multiplicaram como coelhos por todo território nacional.

No que tange ao movimento sindical a realização do $3^{\circ}$ CONCUT, em 1988, na cidade de Belo Horizonte foi um duro golpe nos que defendiam uma maior participação da base e das oposições sindicais nas instancias da central como uma efetiva possibilidade de dificultar o seu processo de burocratização e transformação numa espectadora dos conflitos sociais.

Do ponto de vista político, a crise que culminou no impeachment do Governo Collor precisa ser lembrada como um importante momento em que o clamor das ruas foi canalizado para o terreno institucional. Na principal agremiação política de esquerda, o PT, os militantes ou tendências políticas que defendiam o aprofundamento da crise e a possibilidade de potencializar a partir dali um governo dos trabalhadores, acabaram ameaçados de expulsão ou foram expulsos das fileiras do partido, como foi o caso dos militantes da Convergência Socialista, por terem desobedecido às resoluções partidárias que preconizavam a renúncia do presidente e a posse do então vice-presidente Itamar Franco, e mantido as mobilizações sociais em torno campanha do Fora Collor e a realização de eleições gerais.

Tudo correu dentro das regras institucionais e o governo de Itamar tomou posse, inclusive, com a colaboração política de alguns importantes quadros que atuavam no interior do PT. Nenhum projeto de poder popular, que traduzisse uma perspectiva de autonomia política dos trabalhadores foi potencializado. Pelo contrário, as velhas reivindicações com forte conotação anticapitalista começavam a ser descartadas e a palavra de ordem agora era desideologizar o movimento. 
Mencionar o socialismo, somente nos dias de festa ou documentos próprios da luta interna dos partidos e outras organizações populares e sindicais. Algo muito diferente daqueles dias quando, como escreve István Mészáros, "no Brasil, a ala radical do movimento operário, tanto nos sindicatos quanto nos partidos políticos, teve um papel importante na derrubada da ditadura militar patrocinada pelos Estados Unidos" (MÉSZÁROS, 2002, p. 33).

Claro que alguns episódios internacionais como foram os casos do desmantelamento da URSS, os conflitos que varreram todo o Leste Europeu, as crises chinesas, cubanas, no Oriente Médio influenciaram o desenvolvimento de perspectivas ou tendências reformistas presentes no interior dos movimentos sociais que renegam as reivindicações impossíveis de serem aceitas pelo capital em troca dos ganhos possíveis ou aceitáveis no interior da sociedade capitalista.

Aceitavam assim, progressivamente, o abandono não apenas das teses, mas das estratégias emancipatórias, enquanto se integrava nas estruturas parlamentares e do poder executivo nacional.

Segundo István Mészáros, Rosa Luxemburgo resumiu profeticamente o significado da tendência reformista - e autodestrutiva - do desenvolvimento político da socialdemocracia, acentuando que sua liderança parlamentar "deverá dissolver o setor ativo, com consciência de classe, do proletariado na massa amorfa de um eleitorado" (LUXEMBURGO, Apud MÉSZÁROS, 2002, p. 775).

Rosa escreveu isso, em 1904, se referindo aos partidos da socialdemocracia ocidentais da primeira metade do século XX que se integravam à estrutura parlamentar vigente, aceitando suas imposições coercitivas contra o mundo do trabalho e abandonando quaisquer estratégias de lutas revolucionárias.

Como uma lição que jamais poderia ser esquecida, citamos uma passagem desta contundente crítica ao processo de burocratização e capitulação da esquerda que aparece em sua obra A revolução russa:

[...] só por um exame de toda a assustadora seriedade, de toda a complexidade das tarefas envolvidas, só como resultado da capacidade de julgamento crítico por parte das massas, capacidade que foi sistematicamente liquidada pela socialdemocracia durante décadas sob vários pretextos, só então pode a capacidade genuína para a ação histórica nascer no proletariado alemão. [...] Como discípulos em carne e osso do cretinismo parlamentar, esses socialdemocratas alemães buscaram aplicar à revolução a sabedoria doméstica do berçário parlamentar: para fazer qualquer coisa, você tem que ter primeiro uma maioria. O mesmo, dizem eles, se aplica à revolução: tornemo-nos primeiro uma 'maioria'. A verdadeira dialética das revoluções, contudo, nega esta sabedoria de toupeiras parlamentares: não chegar pela maioria às táticas revolucionárias, mas por táticas revolucionárias chegar à maioria - é assim que o percurso é feito (LUXEMBURGO, Apud MÉSZÁROS, 2002, p. 775).

\section{Relações entre o mundo do trabalho, dos movimentos sociais e a educação}

No Brasil contemporâneo, as condições objetivas ou subjetivas nunca estão propícias e os momentos de se discutir a questão do poder são sempre adiados e deixados para depois, assim acabamos negando a possibilidade de projetarmos a vigência histórica e 
efetivação de uma cultura política que se coloque clara e frontalmente contra a sociedade capitalista, que apresente reivindicações, mobilizações e lutas sociais que não possam ser absorvidas pelo capital.

Pelo contrário, houve um esfacelamento dos movimentos sociais, de sua capacidade de organização e mobilização ao longo de toda década de 1990 até os nossos dias. Claro que houve exceções, como foram os casos do MST, das radicais ocupações realizadas pelos sem-tetos nas mais variadas metrópoles brasileiras, alguns movimentos de desempregados, professores, conflitos envolvendo camelôs, perueiros etc. Mas, sem ter condições de se produzir uma cultura política de ruptura social para o conjunto da classe trabalhadora, uma cultura que nos reconheça como contemporâneos de uma nova fase histórica de ofensiva socialista.

Devemos, neste sentido, nos colocarmos como aqueles que estão dispostos a contribuir com a edificação desta nova cultura política, sabendo que teremos que discutir com muita franqueza com aqueles que vêem apregoando o desenvolvimento de políticas de consenso, o restabelecimento do Estado de bem-estar social, fantasiosas teses de pleno emprego e irresistível crescimento econômico - teses apresentadas com alardes ou mesmo como verdadeiros espetáculos - procurando demonstrar-lhes como tudo isso trazem elementos políticos muito negativos ao necessário processo de re-organização e mobilização das forças políticas e sociais comprometidas com o socialismo.

No desenvolvimento desta cultura socialista o papel dos trabalhadores não produtivos - como é o caso dos professores - é muito importante; quer seja no desenvolvimento de suas lutas cotidianas, quer seja nas ocupações de fábrica e desenvolvimento de projetos de autogestão operária que se afastam da lógica capitalista reinante, como no caso de uma fábrica recuperada pelos trabalhadores ceramistas argentinos:

A fábrica Zanón, rebatizada pelos trabalhadores com o nome de Fasinpat (fábrica sin patrón), é uma indústria de cerâmicas situada na cidade de Neuuquén, na Argentina. Trata-se de uma planta relativamente moderna, que conta com cerca de quatrocentos e oitenta postos de trabalho, ocupa oitenta mil metros quadrados construídos e dispõe de uma área total de nove hectares.Essa fábrica, como várias outras na Argentina, passou das mãos do empresário ao controle autônomo dos trabalhadores em meio a um processo bastante conflituoso.Sob o controle dos trabalhadores, a Zanón passou a fazer parte do universo emergente de organizações de trabalho associado. No âmbito deste universo, que é heterogêneo em suas formas organizativas, situa-se no rol daquelas organizações que apresentam em sua atuação e composição um maior número de elementos democráticos, razão pela qual a literatura, muitas vezes, refere-se a elas como empresas de autogestão. No entanto, podemos considerar a Zanón como uma organização com peculiaridades democráticas surpreendentemente inovadoras e avançadas mesmo neste contexto de referência. Enumeramos as características principais que lhe emprestam certa especificidade: 1) a distribuição igualitária do excedente econômico produzido na fábrica entre os seus trabalhadores, bem como a doação regular de uma fração do mesmo a setores populares da cidade de Neuquén; 2) a idéia, fruto da reflexão dos trabalhadores em seu movimento, de que a fábrica sob seu controle pertence ao povo, o que se encontra em correspondência com a forte interação que ela mantém com a comunidade local e com os movimentos sociais, inclusive em nível nacional; 3) a vigência de um poder firmemente ancorado na base, ou seja, no segmento majoritário do chão de fábrica, que se expressa, 
sobretudo, nas deliberações da assembléia geral, mas que conta também com a participação de outras instancias e mecanismos complementares; 4) a rotação regular e em curto prazo de todos os cargos/funções exercidos pelos trabalhadores na fábrica, técnicas, administrativas e políticas; 5) a perspectiva de futuro que esgrime a consigna de estatização da fábrica bajo control obrero (VIEITEZ \& DAL RI, 2006, p. 185-86).

Aos trabalhadores expropriados pelo capital e que não se deixam iludir pelo canto falacioso do mercado, da justa distribuição da riqueza, dos direitos sociais, da liberdade e da democracia sob a face do capitalismo, não restam alternativas exceto travar essas lutas que desafiam as propriedades privadas, ocupando fábricas, terras, moradias, escolas, universidades, desafiando e questionando com suas ações o sagrado direito de propriedade instituído pelo capitalismo.

Mas, retomando uma questão anteriormente formulada, quando da apresentação dos dados do Inep, quais são as problemáticas e possibilidades proporcionadas pela massificação educacional que se produz na atualidade e que teríamos que mencionar?

Talvez o grande problema, deste processo de massificação, é que ele traz consigo a marca da precarização do trabalho docente, da inexorável diminuição da qualidade do ensino, a transformação das salas de aula em depósitos de crianças, das escolas em purgatórios, cenários de ruínas e espaço propícios ao desenvolvimento de diferentes formas de violências físicas e simbólicas.

Porém, dialeticamente, a educação também está permanentemente associada ao processo de organização da cotidianidade dos indivíduos, no desenvolvimento pleno ou parcial de suas personalidades e, em muitos casos, de sua profissionalização. Educar muitas vezes é a forma mais significativa de inseri-los no universo da vida social, com o compartilhamento de suas normas e valores espirituais, economia e política, cultura e historicidade.

Ela não é neutra ou natural, pelo contrário seus objetivos são tão díspares quanto preservar um determinado modelo social ou comprometer-se com sua subversão. Assim, não compactuamos com os postulados estruturalistas que concebem a escola como reprodutora da estrutura social vigente, negando-lhe quaisquer possibilidades de superá-la.

A escola não pode continuar apenas subordinada a um processo burocrático, disciplinador da vida e controlador do imaginário social. Mesmo num cenário de crise, produtor da fragmentação social é preciso reconhecê-la como produtora da cultura urbana, como um espaço capaz de aglutinar aqueles que estão dispostos a produzirem uma resistência a crescente precariedade da vida social ou uma intervenção capaz de questionar e superar as concepções hegemônicas forjadas nas estruturas tradicionais de poder.

Mas, para que isso possa ocorrer, é fundamental um intenso e molecular trabalho de formação política dos professores e da juventude trabalhadora que povoa esse universo, de engajamento consciente das associações de classe, dos partidos e organizações políticas, populares, dos movimentos sociais, enfim, de todo e qualquer intelectual que se coloque organicamente no interior das lutas pelas transformações sociais e que tenha como compromissos inalienáveis, o fio condutor de sua história colaborar com a construção de um mundo sem explorados, nem exploradores.

\section{Considerações finais}

Nas metrópoles brasileiras, como também em outras espalhadas pelo mundo se expressa um problema de grande magnitude: o direito de estar vivo, pois com o crescimento da violência urbana, amplos setores da população desempregada, semi- 
empregada, empobrecida e proletarizada, que vivem nas periferias e favelas das grandes e médias cidades, passam se deparar com policiais ou delinqüentes trocando tiros como numa guerra convencional e apenas não declarada.

Em muitas cidades está em curso uma política de extermínio, principalmente, de jovens e esta é uma realidade que não nos permite fechar os olhos. Como professores, num momento da história em que a experiência escolar se dissemina na vida de milhões de jovens, crianças e adultos, temos que criar condições de incorporá-los orgânica e ativamente no desenvolvimento de perspectivas de mobilizações sociais e ações políticas.

Ressalte-se também que muitas vezes os professores e os alunos vivem nos mesmos bairros periféricos, assim é preciso estimular que os primeiros participem dos movimentos políticos e culturais que estão em gestação nestes ambientes sociais contribuindo com o questionamento ou mesmo com a superação das lógicas desumanizadoras, competitivas, de um individualismo atroz que o capitalismo produz na efetivação do lucro e de sua própria reprodução.

Experimentando essa cotidianidade, estabelecendo vínculos duradouros no interior destas comunidades, os professores poderão afirmar um novo sentido estrutural para a educação, sua relação com o mundo do trabalho, suas possibilidades históricas e compromissos com a emancipação social.

Merecem atenção, neste caso, a tendência à adoção, por parte das administrações públicas, de estratégias de pronto atendimento da demanda que resultam na precarização das condições de escolarização e em mudanças na própria esfera escolar; e o uso instrumental da escola para a realização de programas assistenciais promovidos por diferentes níveis governamentais, com impactos sobre a estrutura do setor educacional, a dinâmica escolar e as condições de trabalho na escola.

Quanto aos papéis políticos e culturais assumidos pelos professores nesses contextos, interessa avançar na compreensão ampliada da ação política do professor, considerando o desenvolvimento de práticas educativas que têm como centro de suas atenções o impulsionamento do processo de transformações nas relações que se produzem nas metrópoles; a autocompreensão do professor como agente mediador na organização de práxis políticas que traduzam a busca da população pela efetivação e melhoria dos serviços públicos por saúde, educação, segurança, moradia, transportes, etc., não se esquecendo do seu papel de disseminação ideológica e de suas relações com as instituições do Estado, das igrejas e da sociedade civil.

Sabemos que, na atualidade da sociedade capitalista o papel da educação é estabelecer numa escala mundial a disseminação de conhecimentos, práticas, valores políticos, econômicos, morais ou éticos, enfim, uma cultura que possa assegurar a reprodução da ordem social vigente. Todavia é preciso também apontar as possibilidades de ações políticas daqueles que estão inseridos nos processos educativos, de forma que possam contribuir com a superação da subordinação estrutural do trabalho ao capital e dos seus mecanismos de controle social. É muito importante que isto de fato ocorra e contribua com a subtração do poder do Estado e das estruturas tradicionais de poder.

Segundo Gramsci, no mundo capitalista contemporâneo, a luta política encontra-se diluída em todas as esferas da vida social e com a escola não é diferente. Nela - como em outros lugares - se produzem a cultura e as concepções de mundo que as pessoas compartilham. 


\section{Referências}

BOTTOMORE, T. (Org.). Dicionário do pensamento marxista. Rio de Janeiro: Zahar, 1988.

GOHN, M. G. (Org.). Movimentos sociais no início do século XXI: antigos e novos atores sociais. Petrópolis: Vozes, 2003.

GRAMSCI, A. Escritos políticos, vol. 1. Rio de janeiro: Civilização Brasileira, 2004.

MARX, K. O capital, vol. I, crítica da economia política. São Paulo: Nova Cultural, 1988.

MANTOUX, P. A revolução industrial no século XVIII. São Paulo: Unesp, s.d.

MÉSZÁROS, I. Para além do capital - rumo a uma teoria da transição. São Paulo: Boitempo, Campinas: Editora da Unicamp, 2002.

VIEITEZ, C. \& DAL RI, N. M. Educação democrática e trabalho associado no MST e nas fábricas de autogestão. São Paulo: Ícone, 2006.

Artigo recebido em: 29/02/09

Aprovado para publicação em: 15/05/2009 